\title{
Static respiratory compliance in the newborn. II: Its potential for improving the selection of infants for early surfactant treatment
}

\author{
Rosalie A Wilkie, M Heather Bryan, William O Tarnow-Mordi
}

\begin{abstract}
Static respiratory system compliance (Crs) and lecithin/sphingomyelin (L/S) ratios in tracheal aspirates were estimated in two independent groups of mechanically ventilated infants. Crs was measured rapidly at the cotside using a passive expiratory flow technique and $L / S$ ratios were estimated in the laboratory by high performance liquid chromatography. In the reference group of 22 infants, Crs $<1.8 \mathrm{ml} / \mathrm{cm} \mathrm{H}_{2} \mathrm{O} / \mathrm{m}$ predicted surfactant deficiency with a positive predictive value of $100 \%$ and a negative predictive value of $92 \%$. In the validation group of 23 infants, Crs $<1.8$ $\mathrm{ml} / \mathrm{cm} \quad \mathrm{H}_{2} \mathrm{O} / \mathrm{m}$ predicted surfactant deficiency with a positive predictive value of $94 \%$ and a negative predictive value of $83 \%$. Measurement of static Crs is a rapid, non-invasive technique which may usefully supplement current methods of selecting infants at high risk of respiratory distress syndrome.

(Arch Dis Child 1994; 70: F16-F18)
\end{abstract}

Several trials have demonstrated that early use of surfactant in infants judged at high risk of respiratory distress syndrome is more effective than a policy of 'rescue' treatment of infants with established respiratory distress syndrome. ${ }^{1-3}$ However, surfactant is expensive and the financial implications of its wider use will inevitably attract careful scrutiny. Furthermore, in infants who do not need it surfactant might be hazardous. Rapid and reliable methods for selecting infants at high risk of respiratory distress syndrome would be valuable if they could reduce the number of infants treated early unnecessarily without overall loss of clinical benefit. ${ }^{4}$ D'Costa et al predicted respiratory distress syndrome with $100 \%$ sensitivity and $93 \%$ specificity in 115 intubated infants with a laboratory assay using high performance liquid chromatography to measure lecithin/ sphingomyelin (L/S) ratios in tracheal aspirates. ${ }^{5}$ Unfortunately a postnatal assay for L/S ratio would be too slow to assist decisions about surfactant treatment in the first 2 hours of life $\mathrm{e}^{13}$ and prenatal assessment by amniocentesis is invasive and unlikely to be used routinely.

We therefore report a preliminary evaluation of static respiratory compliance (Crs) as a non-invasive, routine measurement to predict surfactant deficiency rapidly at the cotside.

\section{Patients and methods \\ PATIENTS}

Infants who were intubated at birth in two centres were eligible to have tracheal aspirates obtained and those still intubated on arrival in the neonatal intensive care unit were eligible for measurements of static Crs. As the passive expiratory flow technique is not applicable in infants with a continuous air leak through a pleural drain, infants who had a pneumothorax diagnosed and treated before lung function could be measured were excluded.

At Mount Sinai Hospital, Toronto, between January and October 1986 measurements of lung function were made and tracheal aspirates were obtained for measurement of L/S ratios soon after birth in intubated newborn infants (the reference group). At Ninewells Hospital in Dundee between January 1988 and January 1989 lung function measurements and specimens of tracheal aspirate were obtained in a similar group of infants (the validation group). No infants required sedation during measurement of lung function. The studies were accepted as ethical by the University of Toronto ethical committee and the Tayside committee on medical ethics.

\section{LUNG FUNCTION}

Total static Crs was measured during the first 6 hours of life using a passive expiratory flowvolume technique. This method depends on the initiation of the Hering-Breuer reflex by brief occlusion of the airway at or near peak inspiration, leading to inhibition of respiratory muscle activity and is described elsewhere $^{6-9}$ To adjust for body size all Crs values were corrected for length and for birth weight. ${ }^{9}$ Length was measured shortly after birth to within $\pm 1.5 \mathrm{~cm}$ using a tape measure. The method used to measure L/S ratios was based on the separation of lecithin and sphingomyelin in Folch extracts of amniotic fluid by normal phase high performance liquid chromatography. 5 Tracheal aspirates were obtained at intubation within 3 hours of birth. The tracheal aspirates were frozen and stored at $-20^{\circ} \mathrm{C}$. Values of $\mathrm{L} / \mathrm{S}$ ratio $<15$ were taken as indicative of respiratory distress syndrome. ${ }^{5}$

\section{DIAGNOSIS OF RESPIRATORY DISTRESS} SYNDROME

The radiological diagnosis of respiratory distress syndrome was made from a radiograph done in the first 8 hours of life by a doctor 
Characteristics of infants; data are median (range)

\begin{tabular}{lcc}
\hline & $\begin{array}{l}\text { Toronto } \\
\text { (reference group) } \\
(n=22)\end{array}$ & $\begin{array}{l}\text { Dundee } \\
\text { (validation group) } \\
(n=23)\end{array}$ \\
\hline Birth weight $(\mathrm{g})$ & $1115(620-2170)$ & $1240(820-1960)$ \\
Gestation $($ weeks) & $29(25-35)$ & $30(27-34)$ \\
Length $(\mathrm{cm})$ & $38(31 \cdot 5-47 \cdot 5)$ & $37 \cdot 5(31 \cdot 5-43 \cdot 0)$ \\
Uncorrected $\mathrm{Crs}\left(\mathrm{ml} / \mathrm{cm} \mathrm{H}_{2} \mathrm{O}\right)$ & $0 \cdot 7(0 \cdot 2-1 \cdot 8)$ & $0 \cdot 49(0 \cdot 17-0 \cdot 85)$ \\
Crs corrected for body length $\left(\mathrm{ml} / \mathrm{cm} \mathrm{H}_{2} \mathrm{O} / \mathrm{m}\right)$ & $2 \cdot 0(0 \cdot 6-4 \cdot 6)$ & $1 \cdot 2(0 \cdot 5-2 \cdot 5)$ \\
Crs corrected for body weight $\left(\mathrm{ml} / \mathrm{cm} \mathrm{H} \mathrm{H}_{2} \mathrm{O} / \mathrm{kg}\right)$ & $0 \cdot 58(0 \cdot 25-1 \cdot 3)$ & $0 \cdot 34(0 \cdot 14-0 \cdot 67)$ \\
\hline
\end{tabular}

unaware of the patients' LS ratio or lung function results or their subsequent clinical course.

\section{STATISTICAL ANALYSES}

The sensitivity, specificity, positive and negative predictive power of static Crs in identifying values of $\mathrm{L} / \mathrm{S}$ ratio $<15$ and radiological respiratory distress syndrome were calculated. Calculation of each combination of these measures of predictive power requires the selection of a single cut off point for static Crs, which might introduce bias. We therefore also calculated the areas under the receiver operating characteristic (ROC) curves ${ }^{10}$ using all possible values of static Crs, corrected for length and for weight, as cut off points for sensitivity and specificity in predicting surfactant deficiency. ROC curves were derived using a standard commercial spreadsheet (Microsoft Excel).

\section{Results}

Static Crs and tracheal aspirate L/S ratio were measured in 22 infants in Toronto (reference group) and 23 in Dundee (validation group). Their clinical characteristics are shown in the table. Neither group differed significantly. in important clinical characteristics from all the infants ventilated in each neonatal unit during each study period. The 23 infants in the validation group were drawn from a total of 48 infants in whom static Crs was measured during the first 24 hours of life, who are described elsewhere. 9 Figure 1 shows the results for each dataset. In the reference group, values of static $\mathrm{Crs}<1.8 \mathrm{ml} / \mathrm{cm} \mathrm{H}_{2} \mathrm{O} / \mathrm{m}$ correctly classified surfactant deficiency with a sensitivity of $90 \%$, a specificity of $100 \%$, a positive predictive value of $100 \%$ and a negative predictive value of $92 \%$. The predictive
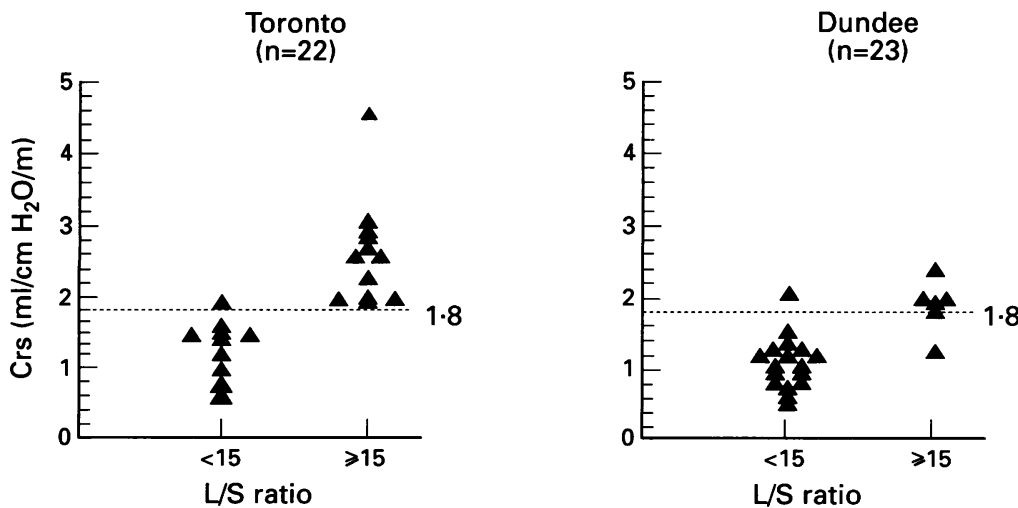

Figure 1 Static Crs in relation to tracheal aspirate $L / S$ ratio (dotted line denotes best cut off in reference population). accuracy of values of static Crs $<1.8 \mathrm{ml} / \mathrm{cm}$ $\mathrm{H}_{2} \mathrm{O} / \mathrm{m}$ for surfactant deficiency was similar in the validation group: with sensitivity $94 \%$, specificity $83 \%$, positive predictive value $94 \%$, and negative predictive value $83 \%$. In the 22 infants in the reference group, $9 / 9$ with static $\mathrm{Crs}<1.8 \mathrm{ml} / \mathrm{cm} \mathrm{H}_{2} \mathrm{O} / \mathrm{m}$ had radiological respiratory distress syndrome and $10 / 13$ with static $\mathrm{Crs} \geqslant 1.8 \mathrm{ml} / \mathrm{m} \mathrm{H}_{2} \mathrm{O} / \mathrm{m} \mathrm{did} \mathrm{not.} \mathrm{Static}$ $\mathrm{Crs}<1.8 \mathrm{ml} / \mathrm{cm} \mathrm{H} \mathrm{H}_{2} \mathrm{O} / \mathrm{m}$ thus correctly classified the radiological diagnosis of respiratory distress syndrome in the first 8 hours with $75 \%$ sensitivity, $100 \%$ specificity, $100 \%$ positive predictive power, and $77 \%$ negative predictive power. As a comparison, in 48 infants at Dundee, ${ }^{9} 26 / 34$ with static Crs $<1.8 \mathrm{ml} / \mathrm{cm}$ $\mathrm{H}_{2} \mathrm{O} / \mathrm{m}$ had radiological respiratory distress syndrome and $9 / 14$ with static Crs $\geqslant 1.8$ $\mathrm{ml} / \mathrm{cm} \mathrm{H} \mathrm{m}_{2} \mathrm{O} / \mathrm{m}$ had not. Static $\mathrm{Crs}<1.8 \mathrm{ml} / \mathrm{cm}$ $\mathrm{H}_{2} \mathrm{O} / \mathrm{m}$ was thus correlated with radiological respiratory distress syndrome in the first 8 hours with $84 \%$ sensitivity, 53\% specificity, $76 \%$ positive predictive value, and $64 \%$ negative predictive value.

To determine whether it was more appropriate to correct static Crs values for length than for birth weight the sets of infants from the two centres were first combined and the accuracy of each correction compared (fig 2). Values of static Crs corrected for length below $1.8 \mathrm{ml} / \mathrm{cm}$ $\mathrm{H}_{2} \mathrm{O} / \mathrm{m}$ correctly classified surfactant deficiency with $93 \%$ sensitivity, $94 \%$ specificity, $96 \%$ positive predictive value, and $89 \%$ negative predictive value. The optimal cut off value for static Crs corrected for weight was $<0.54$ $\mathrm{ml} / \mathrm{cm} \mathrm{H}_{2} \mathrm{O} / \mathrm{kg}$. This correctly classified surfactant deficiency with $89 \%$ sensitivity, $89 \%$ specificity, $92 \%$ positive predictive value, and $84 \%$ negative predictive value. Considering all possible cut offs for each method of correction, the area under the ROC curve was marginally greater for static Crs corrected for length $(0.9568)$ than for static Crs corrected for weight $(0.9506)$.

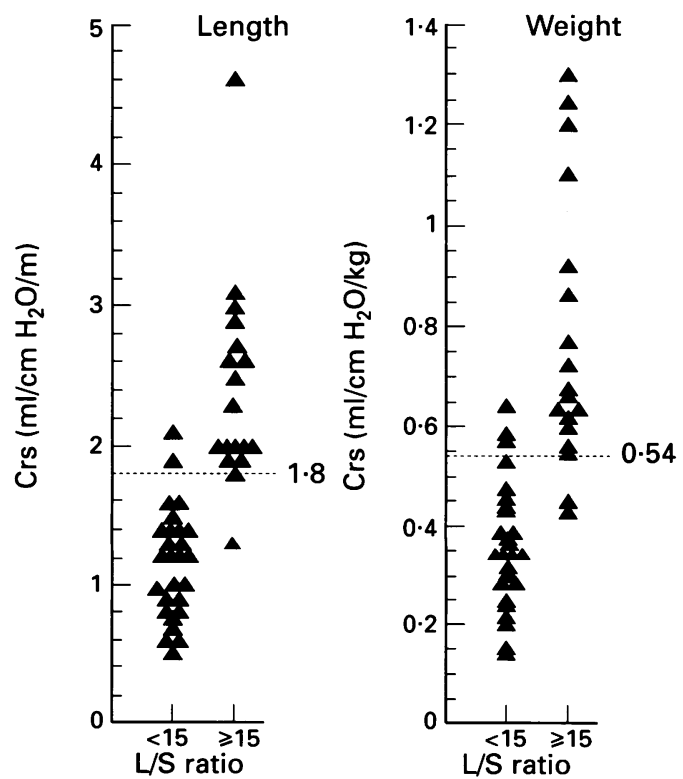

Figure 2 Static Crs corrected to length $(m)$ and weight $(\mathrm{kg})$ in relation to tracheal aspirate $L / S$ ratio (dotted line denotes best cut off in original reference population). 


\section{Discussion}

Early surfactant is undoubtedly effective ${ }^{1-3}$ but is expensive, can be hazardous to administer, ${ }^{1}$ and the long term immunogenicity of both natural and synthetic surfactant is not fully known. ${ }^{11}$ There is thus a clear need to establish rapid, reliable methods for differentiating babies who will benefit from surfactant from those who will not. This is particularly relevant in those neonatal units where babies are frequently intubated and electively ventilated from birth, as in babies without surfactant deficiency the adverse effects of early surfactant might well outweigh the advantages. This could explain reports of acute deteriorations in respiratory function ${ }^{4} 12$ or an apparent increase in medium term adverse outcome $\mathrm{e}^{13}$ associated with the use of surfactant in some centres. Most trials of 'early' versus 'rescue' treatment, including the largest, OSIRIS, ${ }^{1}$ have not attempted rigorously to exclude babies without evidence of surfactant deficiency. Their inclusion may therefore have blunted the comparisons between regimens, masking the value of early treatment and increasing the sample size needed to show a difference in outcome.

The simplest rapid, objective method for differentiating babies at high and low risk of respiratory distress syndrome is a chest radiograph ${ }^{4}$ but this may be unreliable in the first few hours of life. On the other hand, the interpretation of static Crs is itself more reliable if a chest radiograph has excluded important complications such as untreated pneumothorax or malposition of the endotracheal tube in the right main bronchus, which can lead to underestimation of static Crs by about half. This study clearly suggests that early measurement of static Crs accurately predicts surfactant deficiency, using methods which have been independently validated elsewhere. ${ }^{59}$ Static Crs was a slightly better discriminator when corrected for length than for birth weight, in keeping with other studies. ${ }^{912}$ However, early static Crs predicted radiological respiratory distress syndrome less accurately, which may reflect the difficulty of diagnosing clinical respiratory distress syndrome from the chest radiograph alone.

Nevertheless, the central issue is not diagnostic, but whether a rapid, objective measure of risk of respiratory distress syndrome such as static Crs can improve management as measured by major clinical outcomes. This study suggests that static Crs might usefully supplement the chest radiograph in helping to assess rapidly whether to give early surfactant. Elsewhere we have suggested that values of static $\mathrm{Crs} \geqslant 1.8 \mathrm{ml} / \mathrm{cm} \mathrm{H}_{2} \mathrm{O} / \mathrm{m}$ are associated with little or no improvement in lung mechanics within 12 hours after natural surfactant treatment $^{12}$ and may be an indication to consider rapid extubation. ${ }^{9}$ All this points to the need to investigate whether routine measurement of static Crs can enhance the overall clinical care of mechanically ventilated infants. ${ }^{9}$

How practicable would it be to measure static Crs routinely? The level of expertise required to perform and interpret static $\mathrm{Crs}$ measurements is similar to that required for cerebral ultrasound scanning, while the cost of the equipment is about one tenth. Measurements of static Crs usually take less than 10 minutes and could be performed within an hour of birth by clinical staff with suitable training. Further evaluation of the technique in other centres is now needed. If that proved encouraging, the next step would be to organise a multicentre trial to test whether, compared with conventional management, routine measurement of static Crs in mechanically ventilated infants can reduce the use of surfactant while simultaneously reducing or causing no increase in the risk of major adverse clinical events. Such a trial need not be prohibitively large. For example, 400 infants per group would be sufficient to demonstrate a difference in major adverse events from $40 \%$ to $30 \%$ with over $80 \%$ power at conventional statistical significance $(2 \mathrm{p}=0 \cdot 05)$

We thank Mrs Jennifer Cameron for performing the LS assays in tracheal aspirates, the nursing and medical staff in Ninewells Hospital neonatal unit for their support, and Professor Richard Olver for his foresight and encouragement. This work was supported by grants from the Scottish Home and Health Department, Wellcome Trust, Action Research, and Scottish technique is available from WOT-M at cost price.

1 OSIRIS Collaborative Group. Early versus delayed neonatal administration of a synthetic surfactant - the judgement of OSIRIS. Lancet 1992; 340: 1363-9.

2 Soll RF. Overviews of surfactant trials. In: Chalmers I, ed. Oxford database of perinatal trials. Version 1.2, disk issue 7, February 1992, records 5206, 5207, 5252, 5253

3 Halliday HL, Tarnow-Mordi WO. Surfactant replacemen therapy in very preterm infants. Arch Dis Child 1993; 68: 619.

4 Tarnow-Mordi WO. The OSIRIS trial. Lancet 1993; 341:

5 D'Costa M, Dassin R, Bryan MH. Lecithin sphingomyelin ratios in tracheal aspirates from newborn infants. Pediat Res $1987 ; 22: 154-7$.

6 Mortola JP, Fisher JT, Smith B, Fox G, Weeks S. Dynamics of breathing in infants. $\mathcal{A}$ Appl Physiol 1982; 52: 1209-15.

7 LeSouef PN, England SJ, Bryan AC. Passive respiratory mechanics in newborns and children. Am Rev Respir Dis 1983; 129: 552-6.

8 Wilkie RA, Bryan MH. Effect of bronchodilators on airway resistance in ventilator dependent neonates with chronic lung disease. $\mathcal{F}$ Pediatr 1987; 111: 278-82.

9 Tarnow-Mordi WO, Wilkie RA, Reid E. Static respiratory compliance in the newborn. I: A clinical and prognostic index for mechanically ventilated infants. Arch Dis Child 1994; 70: F11-5.

10 Hanley JA, McNeil BJ. The meaning and use of the area under the receiver operating characteristic (ROC) curve. Radiology 1982; 143: 29-36.

11 Strayer DS, Vitetta ES, Kohler H. Anti-receptor antibody 1. Isolation and characterization of the immunoglobulin receptor for phosphoryl choline. F Immunol 1975; 114 $722-7$

12 Stenson BJ, Glover R, Parry GJ, Wilkie RA, Laing IA, Tarnow-Mordi WO. Static respiratory compliance in the newborn. III: Early changes following exogenous surfactant treatment. Arch Dis Child 1994; 70: F19-24.

13 Gibson AT, Primhak RA. Oxygen requirements and artificial surfactant in the premature infant. Early Hum Dev 1992; 28: 190. 